\title{
Procedimiento diagnóstico y terapéutico en la adolescente con tumores de la mama
}

\section{Diagnostic and therapeutic procedure in adolescent girls with breast tumors}

Esther Lombardo-Aburto, ${ }^{1}$ Eduardo Gayón-Vera²

\section{ANTECEDENTES}

Las alteraciones de la glándula mamaria son un aspecto importante en la salud de la adolescente, y causa de preocupación para los padres y la adolescente, por lo que, en la revisión anual, es indispensable la exploración de las mamas y la capacitación para la autoexploración. ${ }^{1}$

Las tumoraciones de la glándula mamaria durante la infancia y adolescencia son raras; ${ }^{2-7}$ su prevalencia es de 3.2 a $13.5 \%$ de las consultas en los servicios de Ginecología pediátrica. ${ }^{3-7}$ Los tumores mamarios más frecuentes corresponden a fibroadenomas. ${ }^{4,7}$ En una revisión de 15 estudios, que incluyó 1797 lesiones mamarias en adolescentes, Neinstein ${ }^{5}$ reportó la existencia de fibroadenomas en el $68.3 \%$ de los casos. El resto de las lesiones fueron, en su mayoría, cambios fibroquísticos y solo en el $0.9 \%$ se encontraron tumores malignos (adenocarcinomas y rabdomiosarcoma metastásico). La patología maligna es excepcional en mujeres menores de 20 años, con una prevalencia de $0.9 \%$ (entre lesiones primarias y metastásicas). ${ }^{3,5}$

En el servicio de Ginecología del Instituto Nacional de Pediatría, del 1 de enero de 2002 al 31 de diciembre de 2013, de 19,986 consultas ginecológicas a niñas y adolescentes, la frecuencia de patología mamaria fue de $4.58 \%$ y correspondió al cuarto diagnóstico más frecuente. ${ }^{4}$

\section{Cuadro 1}

\section{Desarrollo mamario}

El desarrollo mamario sucede con estricto control hormonal y genético. ${ }^{6}$ Durante la cuarta a sexta semanas de vida fetal se desarrollan las yemas mamarias. En el quinto mes de la gestación ya se observa el pezón, la areola y una ramificación de 15 a 25 conductos, cada uno de ellos corresponderá, a partir de la pubertad, a un lóbulo mamario. Al

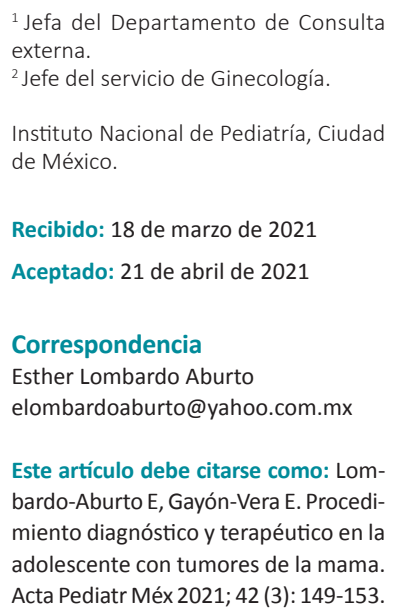

${ }^{1}$ Jefa del Departamento de Consulta externa.

${ }^{2}$ Jefe del servicio de Ginecología.

Instituto Nacional de Pediatría, Ciudad de México.

Recibido: 18 de marzo de 2021

Aceptado: 21 de abril de 2021

Correspondencia

Esther Lombardo Aburto

elombardoaburto@yahoo.com.mx

Este artículo debe citarse como: Lombardo-Aburto E, Gayón-Vera E. Procedimiento diagnóstico y terapéutico en la adolescente con tumores de la mama. Acta Pediatr Méx 2021; 42 (3): 149-153. 
nacimiento, la mama está formada por: el pezón, la areola y los conductos mamarios con células glandulares que forman acinos en los extremos, pero sin un desarrollo completo. Contienen conductos galactóforos, pero no alvéolos, porque estos permanecen hasta la pubertad.

Cuadro 1. Causas de morbilidad general en la consulta de Ginecología del Instituto Nacional de Pediatría (2001-2013)

\begin{tabular}{|c|c|c|}
\hline Causa de morbilidad & $\mathbf{n}$ & $\%$ \\
\hline $\begin{array}{l}\text { Hemorragia vaginal uterina } \\
\text { anormal }\end{array}$ & 5.260 & 26.48 \\
\hline $\begin{array}{l}\text { Afecciones inflamatorias de la } \\
\text { vagina y la vulva }\end{array}$ & 2.698 & 13.58 \\
\hline Dismenorrea & 2.446 & 12.31 \\
\hline Enfermedad beningna de la mama & 910 & 4.58 \\
\hline Síndrome de ovario poliquístico & 641 & 3.23 \\
\hline Alteraciones de la pubertad & 626 & 3.15 \\
\hline Tumor benigno de ovario & 401 & 2.02 \\
\hline $\begin{array}{l}\text { Consejo y asesoramiento en } \\
\text { anticoncepción }\end{array}$ & 244 & 1.23 \\
\hline Síndrome de Turner & 79 & 0.40 \\
\hline Hiperprolactinemia & 46 & 0.23 \\
\hline Todas las demás causas & 6.516 & 32.80 \\
\hline Total & 19,867 & 100 \\
\hline
\end{tabular}

Durante la infancia, la glándula mamaria permanece latente hasta que, en la pubertad, en respuesta a las altas concentraciones de hormonas sexuales, se desarrolla el tejido mamario gracias al efecto de los estrógenos y la progesterona. Los primeros producen el crecimiento del tejido ductal y adiposo, mientras que la progesterona actúa en el desarrollo de la zona lóbulo-alveolar, provocando la diferenciación secretora de conductos y acinos.

La unidad funcional de la glándula mamaria es el alvéolo productor de leche que drena a través de un sistema ramificado de conductos hacia el pezón. Cada lóbulo tiene de 10 a 100 alvéolos que drenan hacia los conductos galactóforos que se unen para formar un seno detrás del pezón.

\section{Clasificación}

1. Tumoraciones benignas

a) Fibroadenoma: es la tumoración más frecuente entre los 12 y 22 años $^{8}$ y constituye más del 90\% de los tumores mamarios. Son masas casi siempre únicas, incluso hasta en el $75 \%$ de los casos, de 2 a 3 $\mathrm{cm}$ de diámetro. Son de consistencia ahulada, móvil, encapsulada, a veces dolorosa, sin secreciones por el pezón ni cambios tróficos de la piel. Afecta con mayor frecuencia los cuadrantes superoexternos, debido a que es la región de la mama con mayor acumulación de tejido funcional. Se pueden detectar al bañarse o en la autoexploración. El tratamiento es quirúrgico. Figura 1

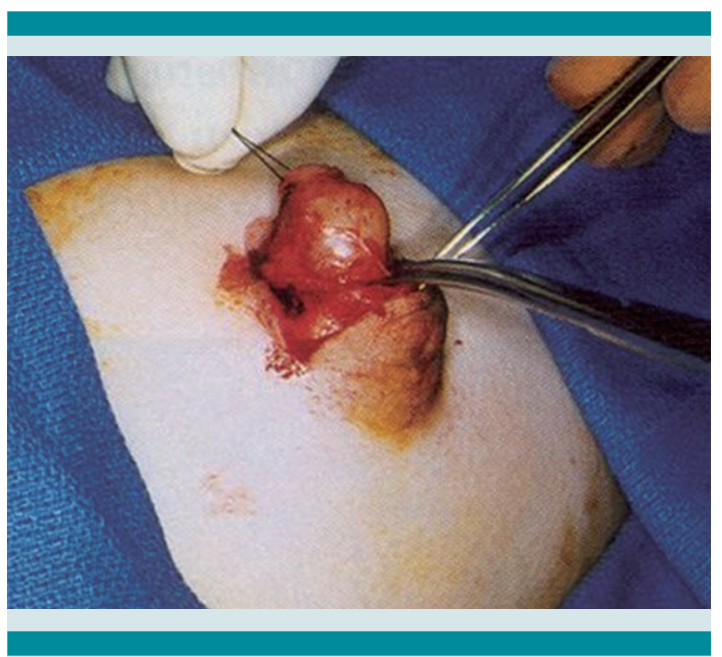

Figura 1. Fibroadenoma de mama típico.

b) Fibroma gigante juvenil: es poco frecuente, se caracteriza por un crecimiento rápido, más de $5 \mathrm{~cm}$, pero pueden llegar a $10 \mathrm{~cm}$. Es asimétrico y comprime los tejidos adyacentes con red venosa colateral y mayor vascularidad, lo que condiciona el 
aumento de la temperatura. El tratamiento ideal es la reducción del tamaño de la lesión (danazol, 100 a $200 \mathrm{mg}$ al día durante 2 a 3 meses), previo a la resección de la lesión residual. Figura 2

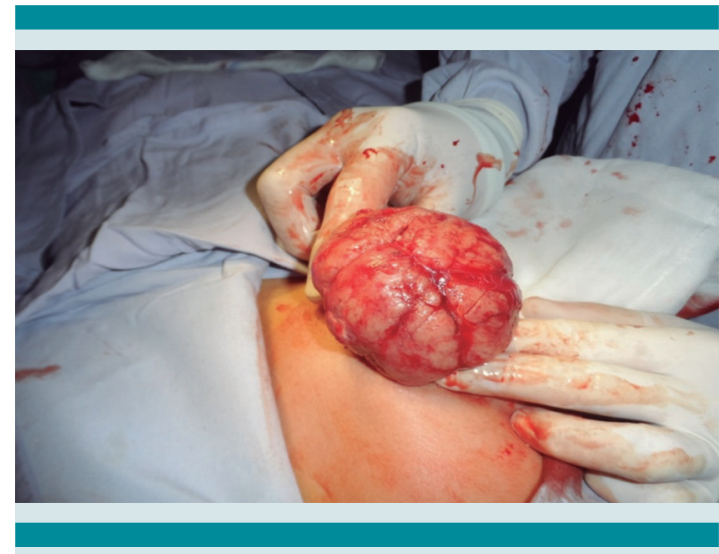

Figura 2. Fibroadenoma gigante de mama resecado después de la reducción de su volumen al cabo de 3 meses de tratamiento con danazol.

c) Tumor Phyllodes benigno: es una neoplasia fibroepitelial con hendiduras en su interior. Es poco común, representa menos del $1 \%$ de todos los tumores mamarios. El término "filoides" proviene del griego y significa "similar a una hoja", hace referencia al hecho de que las células del tumor se multiplican siguiendo un patrón en forma de hoja. Su apariencia es muy Ilamativa debido a su rápido crecimiento, gran tamaño y cambios tróficos y de la coloración de la piel. Es necesario extirparlos y tienen mayor riesgo de recidiva local que otras tumoraciones benignas.

c) Papiloma intraductal: es excepcional en la adolescente. Es una tumoración benigna que se inicia dentro de los conductos galactóforos. Se manifiesta como una masa unilateral debajo de la areola, con telorragia (flujo sanguíneo o sanguinolento que se expulsa directamente a través del pezón). En la adolescente puede confundirse con una ectasia ductal (ocurre cuando un conducto galactóforo se ensancha y sus paredes se engruesan).

\section{Tumoraciones malignas}

Los tumores malignos de la mama pueden ser de origen epitelial o estromal. En la adolescente son muy raros, menos de $1 \%$, de los que el $33 \%$ son primarios de mama, el resto son de origen metastásico.

a) Sarcomas: los tumores estromales suelen aparecer más tempranamente que los adenocarcinomas. El cistosarcoma Phyllodes maligno es el sarcoma más frecuente y es una masa dura, dolorosa, móvil, de crecimiento rápido, que puede alcanzar hasta $20 \mathrm{~cm}$ y ocasionar necrosis, retracción de la piel y secreción hemática por el pezón. El tratamiento es la resección.

b) Adenocarcinomas: son raros en la adolescente. Es una masa dura, no móvil, con "piel de naranja" y linfadenopatía axilar o supraclavicular. Existe antecedente familiar de cáncer.

La mama puede ser un sitio de metástasis y son más frecuentes en la edad pediátrica; los tumores más frecuentes son: linfomas de Hodgkin, linfomas no Hodgkin, leucemias, rabdomiosarcomas y neuroblastomas.

\section{DIAGNÓSTICO DIFERENCIAL}

\section{Con procesos inflamatorios}

Mastitis: se manifiesta con eritema, calor y dolor en una zona amplia de la mama. Deben indicarse antibióticos y antiinflamatorios. Puede asociarse, o no, con la lactancia. Las mastitis agudas no asociadas con la lactancia se observan en mujeres en edad fértil, sin antecedentes de patología mamaria. Cuando no existe infección 
bacteriana, el tratamiento adecuado son los antiinflamatorios.

Absceso: zona eritematosa, indurada, dolorosa en la mama. Requiere tratamiento con antibiótico y, en ocasiones, puede ser necesario el drenaje quirúrgico.

Galactoforitis: proceso inflamatorio de causa desconocida, a nivel de los conductos galactóforos que cursa con retracción y fibrosis. El signo predominante es la umbilicación del pezón. Requiere tratamiento con antibiótico.

\section{Transtornos funcionales (relacionados principalmente con el efecto hormonal)}

Hipertrofia mamaria juvenil: la hipertrofia mamaria juvenil o virginal, también Ilamada macromastia o gigantomastia, es el crecimiento excesivo del tejido mamario como una respuesta anormal a las concentraciones alteradas de hormonas circulantes; puede ser unilateral o bilateral y comienza alrededor de la menarquia. Debido al rápido crecimiento, la piel se observa eritematosa, hipertérmica y edematosa (peau d'orange) o, incluso, puede llegar a la necrosis de la piel. Es poco común y no hay un patrón de referencia para su atención y tratamiento. Se ha reportado con éxito el tratamiento con danazol para disminuir el volumen mamario, pero el tratamiento curativo es la mastectomía con colocación de prótesis mamaria. ${ }^{9}$

\section{Procedimiento diagnóstico}

Ante una masa en la glándula mamaria es fundamental realizar:

1. Historia clínica completa con los datos más importantes:

a) Antecedente familiar de neoplasias mamarias en abuelas, madre y hermanas. b) Antecedentes ginecoobstétricos con desarrollo puberal, menarquia, ciclos menstruales e inicio de vida sexual activa.

c) Antecedentes patológicos, ingesta de medicamentos, de hormonales, radiaciones previas y traumatismos.

d) En el padecimiento actual, una adecuada semiología de los signos y síntomas con el tiempo de inicio, evolución, características de la masa, sitio de localización y signos y síntomas agregados: dolor, cambios de coloración, salida de secreción por el pezón y linfadenopatías. Además de síntomas generales: pérdida de peso, fiebre, astenia, adinamia, hiporexia.

2. La exploración física de las glándulas mamarias siempre debe efectuarse en presencia de la madre o tutora y enfermera. Ofrecer una bata o cubrirla con una sábana. Nunca desvestir a la paciente. Pedirle a ella que lo haga, con la ayuda de la madre.

a) Inspección. Visualizar el tamaño, asimetría, coloración, retracción de la piel o pezones y masas. Debe hacerse con la paciente sentada, con las manos en la cintura y en posición supina, luego con las manos en la nuca.

b) Palpación. Revisar los cuatro cuadrantes con las yemas de los dedos segundo al quinto de la mano derecha, o izquierda, en caso de que el explorador sea zurdo, siguiendo un trayecto en forma de espiral desde el pezón hasta el límite exterior del seno.

c) Revisión del área areolar. Se comprime suavemente para visualizar la salida de secreciones anormales del pezón. 
Lombardo-Aburto $E$, et al. Tumores de la mama en la adolescente

d) Revisión de las regiones de drenaje linfático (axilar y supraclavicular).

\section{Estudios de gabinete}

El ultrasonido es el estudio de imagen más importante para evaluar las masas en las glándulas mamarias de las adolescentes y diferenciar las características sólidas o quísticas. El ultrasonido Doppler es de gran valor para determinar la vascularidad de la lesión.

\section{Procedimiento terapéutico}

La biopsia excisional es el tratamiento más recomendado luego de detectar un nódulo mamario sólido. Los tumores quísticos deben puncionarse para extraer el líquido de su interior y, así, disminuir los síntomas que ocasionan; sin embargo, es muy rara la aparición de quistes en las mamas de la adolescente. No se recomienda la punciónaspiración con aguja fina para la obtención de biopsia previa a la resección.

\section{CONCLUSIONES}

La mayor parte de las lesiones en las adolescentes son benignas; el fibroadenoma es la lesión tumoral más frecuente. El pediatra, que es el primer contacto con la paciente adolescente, debe saber cómo diagnosticar la patología tu- moral mamaria para remitirla oportunamente con el ginecólogo especializado en la atención de pacientes de este grupo etario; así mismo, debe capacitarse para poder sensibilizar a la adolescente acerca de la importancia de la autoexploración de las mamas.

\section{REFERENCIAS}

1. Greydanus DE, Matytsina LA. Breast disorders in children and adolescents. Pediatr Med 2006; 33 (2): 455-502. https://doi.org/10.1016/j.pop.2006.02.002.

2. Ruano Aguilar JM, Duarte Valencia JC, Calderón-Elvir CA. Masas de la glándula mamaria en pediatría. Acta Médica Grupo Ángeles. 2005; 3 (3): 165-77.

3. Schneider SR. Patología mamaria. Rev Chil Pediatr Santiago 1999; 70 (3): 1-4.

4. Gayón-Vera E, Paz-Camacho F, Iracheta-Gerez ML. Atención ginecológica a niñas y adolescentes. Doce años de experiencia en el Instituto Nacional de Pediatría. Ginecol Obstet Mex 2014; 82: 672-87.

5. Neinstein LS. Review of breast masses in adolescents. Adolesc Pediatr Gynecol 1994; 7: 119-29. https://doi. org/10.1016/S0932-8610(19)80114-7.

6. Schiavon ER, Jiménez VC, Robayo TC. Nódulos mamarios en la adolescencia. Acta Pediatr de Méx 2001; 22 (5): 380-88.

7. Raelene D Kennedy, Judy C. Boughey. Management of Pediatric and Adolescent Breast Masses. Semin Plast Surg. 2013; 27 (1): 19-22. 10.1055/s-0033-1343991.

8. Bauer BS, Jones KM, Talbot CW. Mammary masses in the adolescent female. Surg Gyn Obstetr 1987; 165: 63-5. PMID: 3589930.

9. Gayón-Vera E. Danazol as an effective treatment in a girl with juvenile breast hypertrophy. Research. 2014; 1: 755. http://dx.doi.org/10.13070/rs.en.1.755. 